\title{
Adoption of Sustainable Technology in the Malaysian SMEs Sector: Does the Role of Government Matter?
}

\author{
Muhammad Fauzan Abu Bakar ${ }^{1}$, Majharul Talukder ${ }^{2}{ }^{\infty}$, Ali Quazi ${ }^{2}$ \\ and Irfanuzzaman Khan 2,*(D) \\ 1 Faculty of Art and Design, Universiti Teknologi MARA, Shah Alam 40450, Malaysia; mfauzan@uitm.edu.my \\ 2 Canberra Business School, University of Canberra, Bruce, ACT 2617, Australia; \\ majharul.talukder@canberra.edu.au (M.T.); ali.quazi@canberra.edu.au (A.Q.) \\ * Correspondence: Irfan.khan@canberra.edu.au
}

Received: 13 January 2020; Accepted: 10 April 2020; Published: 16 April 2020

\begin{abstract}
This paper looks at the role of government as a novel dimension in the adoption of sustainable technology by small and medium enterprises (SME) in Malaysia. This determinant stems from the fact that, in many transitional economies, private sector organizations encounter resource constraints as a barrier to innovation adoption. This is especially the case with sustainable technology incorporated into business operations. Therefore, third party intervention into the adoption process becomes inevitable and it is considered to make the adoption process more effective. A government has both the power and resources to play a pivotal role in the adoption of sustainable technology. Given this state of affairs, this study examines the government's role as a critical factor in achieving smooth and efficient adoption. The theory of reasoned action (TRA) serves as the theoretical underpinning of this study. The data were collected from a sample of 263 SMEs in Malaysia. Partial least squares structural equation modeling (PLS-SEM) was used to analyze the data. It was found that government policies and subsidies are critical in encouraging the adoption of sustainable technology in Malaysia. This paper discusses the implications for government-driven adoption of sustainable technology, identifies the limitations of the analysis, and avenues of future research in this very relevant and expanding field.
\end{abstract}

Keywords: governmental policy; governmental support; governmental subsidies; sustainable technology; organizational attitude; organizational ethics; adoption behavior

\section{Introduction}

Businesses and organizations require technological innovations that are sustainable, productive, and efficient, in order to compete and meet the demands of products and services for the world's increasing population [1]. Sustainable technology is known as "technology or services that have the potential to radically reduce natural resource use" [2]. Sustainable technology can create a better quality of life for everyone with a minimal life cycle use of natural resources [1,3]. The purpose of sustainable technologies is to create cleaner and environmentally friendly production methods of materials, goods, and services, where resources and energy are used efficiently with only small amounts of waste and emissions [4]. Sustainable technology can contribute to protect against degradation of the environment and reduce dependence on non-renewable energy resources [3]. Furthermore, such technology can improve working conditions, organizational image, and lead to better efficiency in delivering the best opportunities [5].

However, the adoption of sustainable technology entails a high cost component or investment in terms of financial and human resources, while at the same time carrying many risk factors [6,7]. Despite the problems and risks, organizations are increasingly interested in embracing sustainable 
technology and such intentions are considerably growing faster due to the development of local and international environmental standards, regulations, and customers' expectations [8]. Customers prefer purchasing and consuming products that are less toxic, more durable and fulfil the standards of sustainability [9]. Previous studies on the domain of sustainable technology mostly focused on how large organizations utilize it. However, small and medium-sized organizations also have major roles to play concerning sustainability and responsibility, so that an environment that is eco-friendly to the community and the wider society is created [10].

SMEs are considered to be one of the most important sectors in the Malaysian economy [5]. Malaysian SMEs are still in their infancy when it comes to adopting sustainable technology, despite the potential economic, social, and environmental benefits [11]. The Malaysian government has emphasized its efforts, so that, by the year 2020, all valuable resources are not wasted, rural land remains productive and fertile, water is unpolluted, and forest resources have the ability to regenerate and produce the country's development needs [12,13]. With this vision in mind, sustainable technology needs to be developed within Malaysian society and SMEs could benefit from the country's foray into sustainable practices [14].

The government's policies were presented in 2011 as the Malaysian New Economic Model: the enunciated model that is already in place emphasizes such objectives as: reducing the carbon footprint, better assessment of sustainable investments while using non-collateral-based criteria, evaluating the viability of sustainable technology projects, and venturing capital funds to create wealth that can be viably taxed. This will provide SMEs with the opportunity to adopt new technological innovations in the area of sustainable technology that will further enhance the performance of the SMEs and benefit the country [13]. However, research on this aspect of Malaysian SMEs is, to date, very limited in regard to identifying the determinants affecting their adoption of sustainable technology. Much remains to be empirically learned about the government related factors influencing sustainable technology innovation adoption. This study aims to fill this gap in knowledge. The objective of the study is to explore how government policies, support strategies, and subsidies affect SMEs adoption of sustainable technology. A conceptual framework was developed through a review of prior literature, including theories, concepts, methodologies relevant to the government role and sustainable technology adoption among SMEs. The theoretical framework is empirically tested through a quantitative survey of 269 SME owners and managers.

\section{Literature Review}

Malaysia is considered to be a developing country where sustainable technology is easier for organizations to accept, as long as the government provides adequate incentives [15,16]. Advancing in terms of economy, industrialization, and population, Malaysian consumers demand diverse products and services. Because Malaysia has limited resources, businesses and organizations need to find a way to support the demands of consumers. This means increasing productivity and, at the same time, reducing the usage of resources. They also need to ensure that there are sufficient resources for the future population and consumption increase, given that natural resources are declining [16-18]. Currently, majority of Malaysia's industries are simply adding to environmental problems, such as soil erosion and sedimentation, flash floods, destruction of vegetation, air pollution, depletion of natural resources, and the use of building materials that are harmful to human health [19]. Although there are challenges in implementing a sustainable approach in a country that provides low levels of government subsidies, fortunately, the Malaysian government provides adequate incentives for SMEs to implement new sustainable technologies to achieve sustainable development [20].

Malaysia is an emerging country that is currently experiencing strong economic growth and the government is keen to ensure sustainable development as a part of its vision to achieve the status of a developed nation. Malaysia is expecting high growth in GDP, which will increase the demand for sustainable development. The Malaysian government's vision for 2020 focuses on building and developing economically, socially, and environmentally [21,22]. The Malaysian government has 
developed many key policies and strategies over the past 30 years to achieve the country's policy objectives, which are designed to mitigate the issues of security, energy efficiency, and environmental impact to meet the rising the demand for products and services [22]. Malaysia has introduced the "Four-Fuel Diversification Strategy" (FFDS) in 1999 as a plan to utilize more sustainable energy instead of relying only on fossil fuels. Other strategies that the government has brought forward are in place, for example: The Fifth-Fuel Strategy (FFS), Small Renewable Energy Power Programme (SREP), Biomass Generation and Demonstration Project (BioGen), National Biofuel Policy, National Green Technology Policy, and National Renewable Energy Policy. Furthermore, Malaysia constructed the Malaysia Building Integrated Photovoltaic (MBIPV) and Centre for Education and Training in Renewable Energy and Energy Efficiency (CETREE) to promote and make possible a sustainable country. Currently, all efforts to create a sustainable economy are being monitored by the Ministry of Energy, Green Technology, and Water (KeTTHA) [14].

The Malaysian government played a key role in introducing and implementing sustainable technology in an effort to increase the competitiveness of businesses in particular and sustainable Malaysian economy as a whole [23]. The government also introduced incentives and tariffs to promote sustainability amongst the people working in both SMEs and larger organizations. Incentives, such as pioneer status (PS), are given to any organization that makes the effort to pioneer a sustainable innovation. Furthermore, an investment tax allowance (ITA) was also introduced in 2003 to reduce business taxes on any sustainable investment. This initiative aimed to lighten the burden of any organizations that adopted sustainable technology. The Malaysian government established the Malaysian Industrial Development Authority (MIDA) and Energy Commission Agency (ECA) 1967, which are responsible for implementing the distribution of incentives to businesses. Tariffs can also encourage organizations to adopt sustainable technology. It has been proven that tariffs constitute the most effective and cost-effective mechanism to foster sustainable technology in Malaysia. Malaysia introduced a new tariff system in 2017 in order to attract investors and SMEs to adopt sustainable technology in their business activities [14].

A report that was published by the Department of Statistics Malaysia shows that the population of Malaysia is estimated at 32.6 million, increased from 32.4 million as compared to 2018. The current annual growth rate is $0.6 \%$, confirming a steady population growth [24]. The growth in population affirms that more resources will be needed and this in turn will lead to more waste disposal. Therefore, it is important for Malaysians to take on the responsibility to innovate technology with an emphasis on sustainability. Individuals can reduce their usage of chemicals, fuels, and resources but organizations need to have high management capabilities to comprehensively manage and implement sustainable technology $[16,17,25]$. The increase in population will generate both positive and negative impacts on the environment.

Research indicates that the sustainable approach in Malaysia has been deemed to be unsuccessful due to individuals' and organizations' lack of awareness, and low levels of education and income [21]. Moreover, people with higher levels of income and education are more aware of sustainability and environmental issues. By the year 2020, the government aims to become a high-income country and it is crucial for individuals and organizations to become aware of the changes in the environment, as well as adopting sustainability. It is unfortunate that the environment is now endangered, and organizations have to continuously respond to changes in the environment by adapting their products, services and internal processes to survive the competition. Even if the environment is a trigger for changes and a very important setting for finding new solutions, not all of the changes originate outside the organization. In most cases, internal forces can also generate important decisions and actions that could lead to important changes $[21,26]$.

\section{Theory, Research Model and Hypothesis Development}

Theoretical grounding of this research is based on the theory of reasoned action (TRA) [27]. TRA establishes that an individual's behavior is best envisaged by a stated intention to behave 
in a specified manner. Intention, in turn, is predicted by affect or attitude-towards a behavior. Attitudes are sets of beliefs regarding a certain object or an action, which might translate into the intention to carry out the action.

The elegant simplicity of the proposed model stems from the notion that all other predictors of influence on behavior are mediated by the two predictor variables-attitude toward the behavior and social or personal belief. In this research, social or personal belief is conceptualized as ethical belief (organizational ethics) that is characterized by the perceived pressure from salient influencers (for example, government role related variables), weighted by the motivation to comply with the influencers [28]. Thus, attitude and ethics are important determinants that can explain organizational intention to adopt sustainable technology [29]. Moreover, organizational attitude is a result of an affective, cognitive, and behavioral process, independent of an organization's development stages or chronological age [30].

Since this research focuses on Malaysian SMEs, second-party intervention is crucial if organizations are to survive a period of change, due to the high risk and level of investment involved in adopting sustainable technology. The research includes government assistance as part of the theoretical research model (see Figure 1). Three government role related variables (policies, support, and subsidiaries) were derived from various relevant studies on sustainable technological innovations in order to answer the question as to whether the role of government matters in SMEs adopting sustainable technology. These three variables act as predictors of organizational attitude and organization's ethical belief system concerning the adoption of sustainable technology. The combination of factors in this study goes beyond previous research in an attempt to bring together relevant factors that can influence sustainable technology adoption. These variables are integrated into a single model, so that the relationships between the antecedents and the adoption of sustainable technology can be examined.

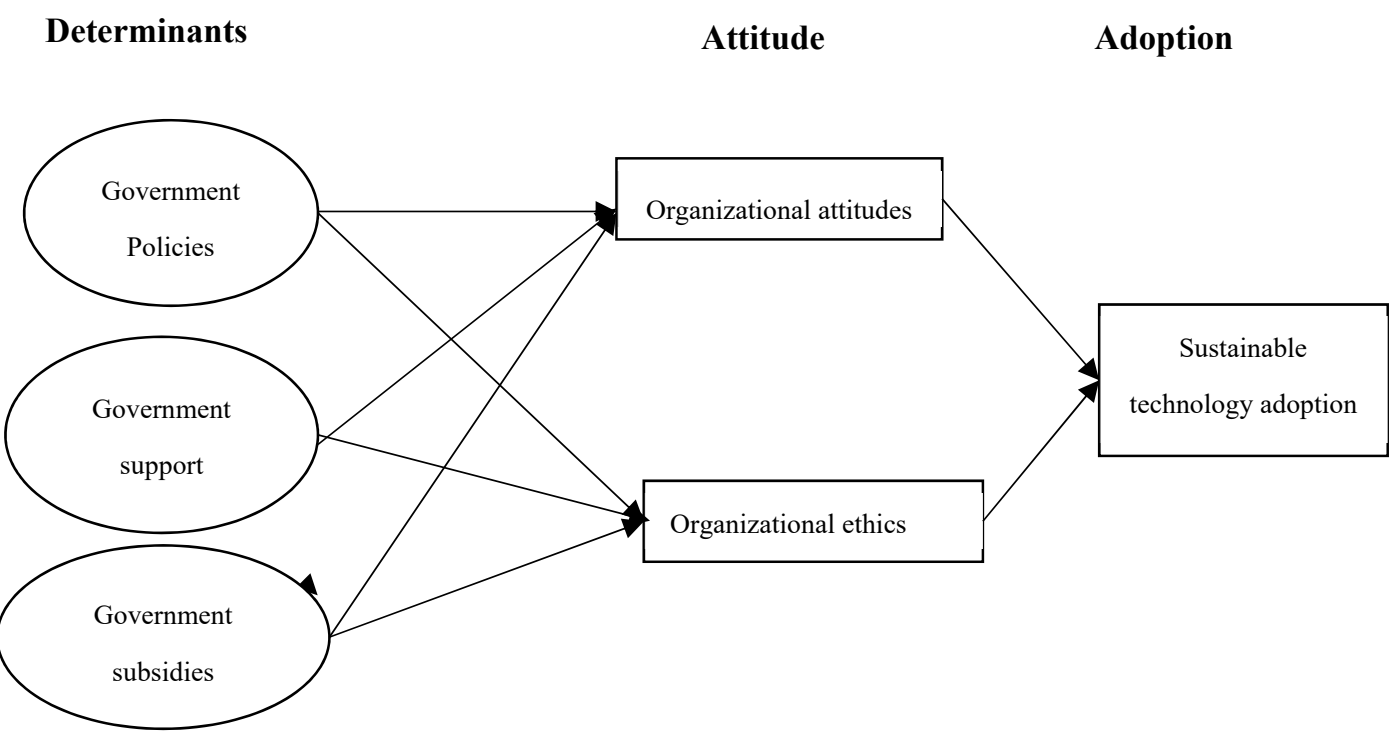

Figure 1. Theoretical Research Model.

\section{Hypothesis Development}

The determinants are classified into three major categories as variables, as stated earlier. These are presented along with the relevant hypotheses that will be tested in close connection with the concerned variables.

\subsection{Government Policies}

Proper government policies are essential if SMEs are to be encouraged to utilize sustainable resources. Government policies require organizations to implement environmental regulations to 
achieve sustainable and environmentally friendly outcomes, so that dependence on natural resources is curtailed [31,32]. Governmental sustainability policies can increase organizations' access to affordable new sustainable technology and provide new resources that function to reduce adverse environmental outcomes [23]. A proper policy can ensure the long-term reliability and security of natural resources for sustainable social and economic development. It is known that many businesses and organizations in developing countries are still too dependent on natural resources. Government sustainability policy must be strictly implemented, so that institutions are obliged to use sustainable technology in their daily operations [33]. It is essential for the government to introduce a sustainability policy at an early stage, so that the benefits of sustainable technology can be realized soon after $[33,34]$. Therefore, the following hypothesis is proposed:

Hypothesis 1 (H1). Government policies have a significant relationship with organizational attitudes and ethics.

\subsection{Government Support}

Governmental support is an important factor that will influence the adoption of sustainable technology by Malaysian SMEs [35]. Such support includes encouragement given to the SMEs and allocation of adequate resources [36]. Government support can have several purposes: educate organizations regarding the use of sustainable technology; change organizational behavior towards sustainability; and, establish a more conscious and permanent relationship with the natural environment [35]. Studies indicate that government support is positively related to the SMEs' adoption of sustainable technology [37]. In this context, government support might facilitate SMEs' utilization of technological innovations. Conversely, a lack of support is seen as a critical barrier to adopting sustainable innovation [38]. Thus, organizations with insufficient knowledge and skills can cause serious damage to the natural environment. Organizations tend to innovate more if they believe that the government will value such initiatives [39]. The role of government's support in terms of helping organizations to be ready for sustainable technology is evaluated by the proposed hypothesis:

Hypothesis 2 (H2). Government support have a significant relationship with organizational attitudes and ethics.

\subsection{Government Subsidies}

Subsidies are often considered to be a powerful driver of innovation adoption [40,41]. For example, tariffs on sustainable technology can help SMEs to adopt and use such technology [33]. Tariffs have proven to be the most effective and cost-effective mechanism for fostering sustainable technology, rather than other policy mechanisms, such as quotas, direct incentives, or voluntary goals [14,32]. Government subsidies and incentives need not only be financial in nature. Innovative, non-monetary incentives, such as providing public recognition, awards, changing job titles, and organization title scan be equally effective as financial subsidies over the long-term [42]. Therefore, the following hypothesis has been posited:

Hypothesis 3 (H3). Government subsidies have a significant relationship with organizational attitudes and ethics.

\subsection{Organizational Attitudes}

Attitude is known as a pre-disposition to respond favorably or unfavorably to an object, person, event, or institution. Thus, attitude is the function of behavioral beliefs and evaluation of outcomes [27]. Past studies indicate that attitude positively influence behavioral intentions and this relationship has received substantial empirical support $[43,44]$. Specifically, organizations or employees are more likely 
to execute a behavior if they possess a positive attitude and are more likely not to do so when they possess a negative attitude [45]. Attitude can be explained through three categories. The first-affective attitude-is commonly related to the human emotional state. An affective attitude is the occurrence of human reactions when encountering significant relationships with others or the environment [46]. An affective attitude tends to rely on the emotions that are inherent in an organization and focus on their perceptions of the environment. Also referred to here are the emotions or feelings of satisfaction, favorability, or likeness [47].

The second category is concerned with cognitive attitude. Organizations that have cognitive attitudes towards the environment believe that actions can contribute to the greater good, for themselves and their surroundings. They might not feel that their actions may help them to develop a better understanding and take an approach that leads to a better and more sustainable life [48]. A cognitive attitude consists of beliefs, ideas, and thoughts around a target object, organization, or situation [47].

The third and last category is that of behavioral attitudes. Behavioral attitudes can be explained as the obligation that is felt by organizations' personnel to change their behavior by acting for a purpose or benefit. It is associated with the responsibility that organizations' staff feel in acting on a certain value [29]. An employee's capabilities to react and perform a certain action, whether to approach or avoid a certain situation, are their behavioral instincts. Behavioral attitudes also influence the socioeconomic system in which decision-making occurs and they can change an organization's structural set up [47,49]. On this basis, the following hypothesis has been proposed:

Hypothesis 4 (H4). Organizational attitudes have a significant and positive relationship with the adoption of sustainable technology.

\subsection{Organizational Ethics}

Ethical belief can be described as people's sense of right and wrong. Scholars have categorized ethical belief into three main facets that are linked to studies of sustainability and the environment. The first face is that of anthropocentric belief. Anthropocentric organizations value the environment for its material and physical benefits to humans [50]. These organizations respond to informative arguments that can explain the benefits of sustainability. Furthermore, environmental incidents causing property/product loss and damage have also exposed organizations to well-founded reasons for adopting a sustainable approach towards business. Anthropocentric organizations tend to focus on the present or short-term benefits [51].

The second facet is concerned with the concept of eco-centrism. Eco-centric organizations value nature for its own sake and for its beauty [50]. They respond to emotional approaches portraying the importance of environmental conservation. They believe in future benefits over the long-term, as they are more pro-environment and focus on enhancement and preservation [52]. An eco-centric attitude involves individuals and organizations appreciating the environment as an integral living being, which needs to be protected and respected. The third facet is altruism, which means valuing the community and social cohesion. An altruistic attitude is considered to be a key component in the successful adoption of sustainable practices. Organizations with an altruistic attitude act so that others may benefit [50-52].

Similarly, sustainability is tied to the concept of selflessness; sustainable measures are taken up to save the environment for the safety of others [52]. Organizations with a high degree of altruism are always open to change, and they care for the natural environment [53]. Altruism has always been associated with a strong moral sense and human conscience, along with the kind of human intellectual power that contributes to the healthy development of society $[53,54]$. Therefore, the following hypothesis is developed: 
Hypothesis 5 (H5). Organizational ethics have a significant and positive relationship with the adoption of sustainable technology.

\section{Research Methodology}

This study focuses on the adoption of sustainable technology by SMEs operating in Malaysia using quantitative methods for data collection. A structured questionnaire was formulated to collect quantitative data. The questionnaire was developed by considering the target respondents, the owners or senior level managers of SMEs. The initial stage of developing questions for inclusion in the questionnaire involved obtaining three research experts' opinions on the topic area of this study. These comments were then taken into consideration when revising the relevant questions. The study instruments were pre-tested in order to identify and modify the items that the respondents tended to misinterpret, skip over, or improperly respond to. The final questionnaire was prepared after incorporating the changes based on the outcomes of the pretesting.

The questionnaire includes the six (6) constructs defined under the proposed conceptual framework, including government policies, government support, government subsidies, attitude, ethics, and adoption of sustainable technologies. All of the measurement items for the aforementioned constructs have been adopted from the extant literature. The wording of some of the measurement items was contextualized to suit the purpose of this study. In total, thirty-two (32) measurement scale items were selected and used to measure the six constructs of the proposed theoretical framework. Questions that were designed to elicit attitude, organizational ethics, government policies, government support, and government subsidies were structured, as suggested by Ajzen and colleagues [27], based on 7-point Likert scale. Adoption of sustainable technology was measured using the subjective measures of technology use, which include self-reported usage measures of the frequency of using sustainable technology [55]. The survey questionnaire is attached in the Appendix A.

Information that was related to the SMEs was obtained from the SME Corporation Malaysia, which provided a list of 8764 SMEs. A paper-based survey questionnaire was sent by postal mail to 2000 randomly selected SMEs. A screening question was included in the questionnaire to identify whether the potential respondent is familiar with the concept of sustainable technology. SME owners or managers who are familiar with the concept of sustainable technology were asked to proceed with completing the questionnaire. Initially, 159 responses have been received. Further, follow up phone calls and emails yielded 110 more responses. Thus, a total of 269 completed questionnaires were received, out of which 263 were deemed to be usable for analysis. A response rate of $13.15 \%$, which is common in the research of such areas was achieved. The respondents of the survey are mostly owners or senior level managers of the respective SMEs in accordance with the requirements of this research.

This research used the partial least squares structural equation modeling (PLS-SEM) algorithm, which emphasizes the indicator having stronger reliability levels through the generation of composite reliability, in order to test the reliability of the variables [56]. In PLS-SEM, the variables should have an outer loading that exceeds 0.50 in order for them to be interpreted as absolutely important. Any variables that have values below 0.50 will be considered as strong candidates for removal, unless, according to experts' opinions, they can be retained [57,58]. The values of composite reliability, which are between 0.70 and 0.90 , can be regarded as satisfactory in advanced theoretical research [58].

The research data were further tested for their convergent and discriminant validity. The average variance extracted value (AVE) is determined to measure and establish the variables' convergent validity. The AVE is equivalent to the communality of a construct. The AVE, which is 0.50 or higher, indicates that, on average, the construct explains more than half of the variance of the variables. On the other hand, an AVE of less than 0.50 means that, on average, there are more errors in the items than the variance that is explained by the construct. Discriminant validity is the extent to which a variable is truly distinct from other variables according to empirical standards. This shows that a variable is unique, and it could capture the phenomena which is not represented by other variables in the 
theoretical research model. The Fornell-Larcker criterion is a conservative approach that is used in assessing discriminant validity. It is a method that compares the square root of all AVE values with the latent variable correlations. The square root of each variable's AVE should be greater than its highest correlation with any other variables [57].

\section{Data Analysis and Findings}

\subsection{Analysis of Organizational Characteristics Data}

This section analyzes the organizational characteristics data and explains the descriptive statistics in the form of a frequency table. Descriptive data constitute an important source of information about SMEs' perceptions regarding the adoption of sustainable technology. This section provides a description of respondents' profiles concerning the type of organization that they work for, how old the business is, the number of employees and the annual sales turnover. The respondents from service-oriented organizations constituted $43.3 \%$, while the respondents from product-oriented organizations represented $56.7 \%$ of the cohort.

A total of 29 organizations (11.0\%) that participated in the survey had been established for more than 20 years, while $8.4 \%$ had been operational for 16 to 20 years; $17.9 \%$ had run their businesses for 11 to 15 years; and, another $35.4 \%$ for a period of six to 10 years. The remaining $27.4 \%$ represented a group of newcomers in the business world, having started their businesses less than five years ago. According to SME Corporation Malaysia, SMEs are divided into three categories-micro, small, and medium-each with their own characteristics. Micro organizations have fewer than five employees and accumulated annual sales turnover of less than MYR300,000. The small-scale organizations have between five and 75 employees, with MYR300,000 to MYR15 million sales turnover annually. Medium-sized organizations have 75 to 200 employees and generate sales turnover of MYR15 million to MYR50 million a year. The survey respondents mostly came from organizations with fewer than five employees $(43.3 \%)$, followed by organizations with five to 75 employees (40.7\%) and medium-sized organizations $(16.0 \%)$, as per the data provided in Table 1. Although most of the organizations participated in this survey were small-scale concerns, the highest percentage of respondents came from businesses with sales turnover of between MYR300,000 and MYR15 million (44.1\%), followed, in turn, by less than MYR300,000 a year (39.5\%) and MYR15 million to MYR50 million per year (16.3\%).

Table 1. Respondents' Demographic Information.

\begin{tabular}{cccc}
\hline Characteristic & & Frequency & Percentage (\%) \\
\hline Type & Service-oriented & 114 & 43.3 \\
& Product-oriented & 149 & 56.7 \\
Age & More the 20 years & 29 & 11.0 \\
& 16 to 20 years & 22 & 8.4 \\
& 11 to 15 years & 47 & 17.9 \\
& 6 to 10 years & 93 & 35.4 \\
Employees & Less than 5 years & 72 & 27.4 \\
& 75 to 200 employees & 42 & 16.0 \\
Sales & 5 to 75 employees & 107 & 40.7 \\
& Less than 5 employees & 114 & 43.3 \\
& MYR15 million to MYR50 million & 43 & 16.3 \\
TYR300,000 to MYR15 million & 116 & 44.1 \\
& Less than MYR300,000 & 104 & 39.5 \\
\end{tabular}

\subsection{Evaluation of Reflective Measurement Models (PLS-SEM)}

The data instruments were further tested using the PLS algorithm to evaluate the reflective measurement models. The PLS path model is used to review the relevant evaluation criteria for the measurement model as well as the appropriateness of the report's results. By using PLS-SEM, the data 
can be measured while using predictive capabilities in the theoretical research model to judge the model's quality. The model could assist the researcher in evaluating the reliability and validity of the construct's measures. The assessment for the credibility of the model includes composite reliability, which is used to evaluate two things: firstly, internal consistency, individual indicator reliability, and average variance extracted (AVE); and secondly, convergent validity and discriminant validity. Table 2 summarizes the validity and reliability of the model.

Table 2. Validity and reliability of the model.

\begin{tabular}{cccc}
\hline Variables & Composite Reliability & Convergent Validity (AVE) & Discriminant Validity \\
\hline Attitudes & 0.973 & 0.878 & Yes $(0.937>0.204)$ \\
Ethics & 0.954 & 0.806 & Yes $(0.898>0.394)$ \\
Governmental Policies & 0.954 & 0.805 & Yes $(0.897>0.780)$ \\
Governmental Support & 0.958 & 0.822 & Yes $(0.906>0.858)$ \\
Governmental Subsidies & 0.967 & 0.854 & Yes $(0.924>0.858)$ \\
Adoption of Sustainable & 0.944 & 0.722 & Yes $(0.879>0.387)$ \\
Technology & & & \\
\hline
\end{tabular}

\subsection{Composite Reliability}

Internal consistency reliability is also known as composite reliability. It is the modern version of Cronbach's Alpha, which provides the estimation of reliability that is based on inter-correlations of the observed indicator variables. The composite reliability ranges between 0 and 1 . Higher values indicate higher levels of reliability. Composite reliability values within the 0.60 to 0.70 range are acceptable in an exploratory research; while, in a more advanced research, the values between 0.70 and 0.90 are regarded as satisfactory [59]. The composite reliability values of 0.973 (attitudes) and 0.954 (ethics) demonstrate that both organizational attitudes' and ethics' variables have high levels of internal consistency reliability, as shown in Table 2. The same results are also presented for governmental assistance variables with high levels of composite reliability values of 0.954 (policies), 0.958 (support), and 0.967 (subsidies), whereas, adoption has a reliability value of 0.944 . All of the variables that have a high level of composite reliability could proceed with the analysis.

\subsection{Convergent Validity}

The average variance extracted value (AVE) is used to measure and establish the convergent validity of the variables. The AVE is equivalent to the commonality of a construct. The AVE, which is 0.50 or higher, indicates that, on average, the construct explains more than half of the variance of the variables. On the other hand, an AVE of less than 0.50 indicates that, on average, there are more errors in the items than the variance that is explained by the construct. The convergent validity assessment depends on the AVE values, as per criteria. The following AVEs are above the required minimum level of 0.50: attitudes (0.823), ethics (0.771), policies (0.706), support (0.766), subsidies (0.805), and adoption (0.722). Thus, the independent and dependent variables of the theoretical research model have high levels of convergent validity.

\subsection{Discriminant Validity}

Discriminant validity is the extent to which a variable truly differs from other variables according to empirical standards. This shows that a variable is unique, and it could capture the phenomena that are not presented by other variables in the theoretical research model. The Fornell-Larcker criterion is a conservative approach that assesses discriminant validity. This method compares the square root of all AVE values with the latent variable correlations [57]. Thus, the square root of each variable's AVE should be greater than its highest correlation with any other variables. The final results of the Fornell-Larcker criterion assessment with the square root of the AVE are assembled diagonally. Then the value is compared to the correlation values of each column. For the result, the square root of the adoption variable is greater than the highest values of other correlations $(0.879>0.387)$. The same patterns are also applied to other variables: attitudes $(0.937>0.204)$, ethics $(0.898>0.394)$, 
policies $(0.897>0.780)$, support $(0.906>0.858)$, and subsidies $(0.924>0.858)$. It can be concluded that all of the criteria for the model's evaluation are satisfied and the results support the reliability and validity of the measures.

\subsection{Evaluation of the Theoretical Research Model}

The theoretical research model that represents the underlying theory of the path model. The results could determine how well the empirical data support the theoretical framework and whether the theory can explain the phenomenon [58]. The theoretical research model is further examined after confirming the reliability and validity of the construct. The PLS-SEM analysis has been used to determine the structural model relationships, which also represent the hypothesized relationships among the variables. Although the path coefficient can estimate the significant values of a variable, the significant values still depend on their standard error, which could be obtained through bootstrapping. In bootstrapping, the subsamples are randomly selected from the original set of data. Bootstrapping is applied to compute the $t$ value. The empirical $t$ value has to be larger than the critical value to determine whether the coefficient is significant at a certain error probability. After calculating the $t$ values, any value that is more than 1.65 (significance level $=10 \%$ ) is considered to be significant.

Table 3 shows the $t$ values for all of the path coefficients and presents them as either significant or non-significant. The PLS path indicated that the relationship between attitudes and adoption is very significant with the $t$ value of 4.348 ( $>1.65)$. Organizational ethics also demonstrates a strong significant relationship with adoption with the $t$ value of 3.440 ( $>1.65)$. From the perspective of attitudes, policies is the only variable that has a significant result of $1.825(>1.65)$, whereas, for organizational ethics, only subsidies reveal a significant relationship of $2.715(>1.65)$.

Table 3. Results of the structural model path coefficients.

\begin{tabular}{cccccc}
\hline & $\begin{array}{c}\text { Path } \\
\text { Coefficients }\end{array}$ & t Values & Significance Levels & p Values & Comments \\
\hline Attitude $\rightarrow$ Adoption & 0.340 & 4.348 & $* * *$ & 0.000 & Supported \\
Ethics $\rightarrow$ Adoption & 0.433 & 6.262 & $* * * 00$ & Supported \\
Policies $\rightarrow$ Attitude & 0.303 & 1.825 & $* *$ & 0.068 & Supported \\
Policies $\rightarrow$ Ethics & 0.067 & 0.402 & NS & 0.688 & Not supported \\
Support $\rightarrow$ Attitude & -0.016 & 0.074 & NS & 0.941 & Not supported \\
Support $\rightarrow$ Ethics & -0.169 & 0.821 & NS & 0.412 & Not supported \\
Subsidies $\rightarrow$ Attitude & -0.098 & 0.534 & NS & 0.593 Not supported \\
Subsidies $\rightarrow$ Ethics & 0.486 & 2.715 & $* * * 007$ & Supported \\
\hline$* * *$ Correlation is
\end{tabular}

*** Correlation is significant at the $p<0.01\left(2\right.$-tailed); ${ }^{* *}$ Correlation is significant at the $p<0.05$ level (2-tailed); *

Correlation is significant at the $p<0.10$ level (2-tailed).

Apart from computing the $t$ value, this research presents the $p$ values that correspond to the probability of erroneously rejecting the null hypothesis. The $p$ values should be $p<0.001, p<0.05$, and $p<0.10$ in order for the $p$ values to be considered as significant. Any values that are higher than 0.10 will be considered to be non-significant. The variables that have significant values $(p<0.01)$ are attitudes $\rightarrow$ adoption, ethics $\rightarrow$ adoption, and subsidies $\rightarrow$ ethics, whereas, policies $\rightarrow$ attitudes have a slightly significant $p$ value of $0.068(p<0.10)$.

\section{Discussion of the Results}

The PLS-SEM path analysis showed that all variables accounted for $72.2 \%$ of the variance in organizations' acceptance of sustainable technology. Table 3 illustrates the path coefficients and constant for PLS-SEM algorithm and the significance of each independent variable in the model in predicting the dependent variable. Based on the findings, this research has found that government policies and subsidies are important in explaining Malaysian SMEs' perceptions of the adoption of sustainable technology. The data from the PLS-SEM path analysis indicated that organizational attitudes and ethical beliefs have a high coefficient and are able to predict the adoption of sustainable technology. A summary of the results are discussed below: 


\subsection{Hypothesis-1}

The results indicate that government policies have a significant and positive effect on organizational attitude $(* * p<0.05)$. However, the relationship between government policies and organizational ethics is insignificant $(p>0.05)$. The result implies that favorable policies lead to favorable attitude towards sustainable technology, consequently enhancing the scope for adoption. Thus, the result opens up avenues for government policy discussion that is related to sustainable technology adoption usage among the SMEs. The government can influence organizational attitudes by introducing new policies that generate positive feelings towards sustainability, which could encourage the adoption of sustainable technology [33,34].

\subsection{Hypothesis-2}

The findings indicate the insignificant relationship between government support and organizational attitudes $(p>0.01)$ and ethics $(p>0.01)$. This finding contradicts with past studies, which considered governmental support to be a significant factor concerning the adoption of sustainable technology by Malaysia's SMEs $[35,60]$. The insignificant findings between these variables point towards an interesting state of affairs and require further exploration. One of the primary reasons behind insignificant relationship could be due to the fact that in Malaysia, the government has been known to promote the usage of various sustainable technology, and government is expected to provide support for using sustainable technology among SMEs. Thus, support is not considered to be a distinct parameter in the minds of SME owners and managers concerning their adoption behavior.

\subsection{Hypothesis-3}

The results show that government subsidies have a direct relationship with the ethics $\left({ }^{* * *} p<0.01\right)$ and an insignificant relationship with the attitude $(p>0.05)$. The results indicate the Malaysian government can help to improve the confidence of the owners of SMEs by providing subsidies, which will allow the SMEs to operate more efficiently, embrace cleaner technologies, and nurture ecological relationships with their suppliers and consumers [61-63], thus improving their overall competitiveness. This would allow for them to move away from the traditional profit-driven orientation and nurture ethical engagement in terms of sustainable technology adoption $[20,64]$. Thus, subsidies and incentives can be provided to SMEs through the introduction of sustainable technology that could lighten the burden and risk factors of employees, suppliers, and clients.

\subsection{Hypothesis-4 \& 5}

The result shows that attitude $\left({ }^{* * *} p<0.01\right)$ and ethics $\left({ }^{* * *} p<0.01\right)$ significantly influence the adoption of sustainable technologies. The result is consistent with the previous studies and supports the notion that attitudes have a positive relationship with an organization's decision to adopt new technologies [65-67]. The result also implies that by improving organizational attitudes and organizational ethics, it is most probable that the adoption of sustainable technology will increase. The results of this research is aligned with the work of Corral-Verdugo and colleagues [52,53], specifically with regard to the statement that the altruistic attitude of selflessness is always open to change, which could have an impact on individuals and organizations that care for others. Organizations are starting to change their approach in following legislated sustainability standards, because they now know that using dangerous materials and resources can endanger the health and safety of others. This demonstrates that SMEs ranging in size from micro, small, or medium are aware of others' safety. Figure 2 demonstrates the final research model based on the PLS-SEM algorithm and the significance of each independent variable in the model in predicting the dependent variable. 
Determinants

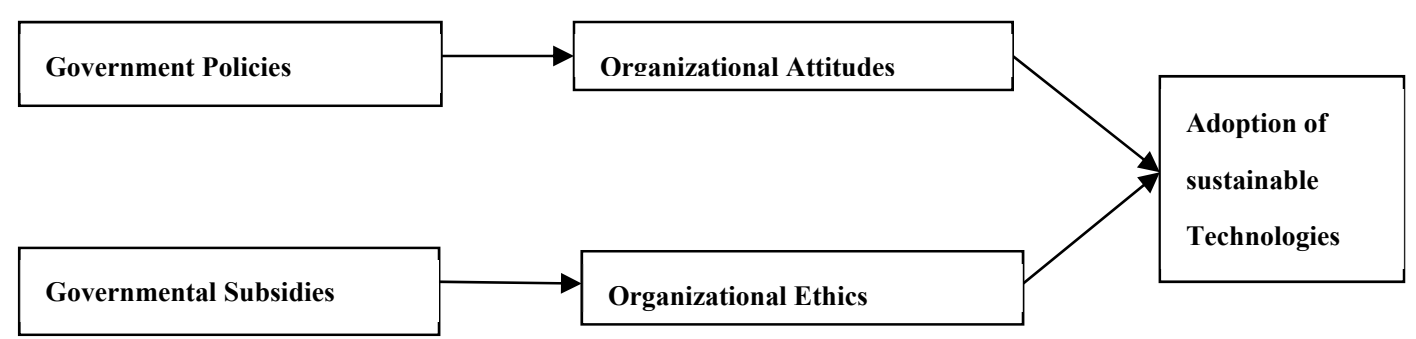

Figure 2. Partial least squares structural equation modeling (PLS-SEM) Path Theoretical Research Model.

\section{Conclusions and Implications}

This research proposes a clearly outlined model with new variables, in it that can be used for further research in technology adoption related investigations. This paper sheds light on the role of government policies, government subsidies, organizational attitudes, and organizational ethics concerning sustainable technology adoption by SMEs in a researchable fashion. Most importantly, this paper addresses an apparent gap in the literature concerning the sustainable technology adoption behaviors of SMEs. Organizational attitudes and ethics are the essential elements that complete the process of their sustainable technology adoption. The parsimony of the proposed research framework makes it easy to apply in a different context. This framework provides a well thought out structure for exploring how government roles play a vital role in SMEs' sustainable technology adoption behaviors. Thus, the model that was employed in this research study can potentially be applied to many sustainable technology adoption issues and organizational dilemmas. Future studies may seek to examine the role of government in the context of large organizations using the proposed framework. The determinants investigated in this study can assist the Malaysian government to better comprehend the issues and act accordingly.

Therefore, it is suggested that the Malaysian government should implement a sustainability policy for SMEs to adhere to, and it must also recognize the organizational attitudes and ethical considerations that could influence the SMEs adoption of sustainable technology. The findings of this research will help the Malaysian government to identify important factors and provide favorable conditions that will make the implementation of sustainable technology possible.

For SMEs, organizational attitudes and ethics are the essential elements that complete this process. If SMEs do not treat a sustainable technology positively, it will not be useful, as eventually they will give up halfway and this represents wasted time and effort. SMEs can create their own awareness campaigns regarding sustainable technology that are enjoyable, easy to use, and also introduce support programs that may trigger employees' interest.

Promoting sustainable technology in a way that can enhance emotions and a sense of responsibility towards the environment might lead to a better acceptance of sustainable technology. The effort to promote sustainable technology within Malaysian SMEs will not go to waste, as employees are revealing a greater sense of care for the environment and positively perceive the adoption of such technology. The government and NGOs should undertake a major strategic effort to encourage SMEs to be more sustainable for the sake of a more secure future for the next generations. They need to guide and design communication strategies for SMEs that can successfully diffuse sustainable technology.

\section{Limitations and Future Research}

This study has analyzed the adoption of sustainable technology by Malaysian SMEs. If the same research is carried out in another setting, different results may be generated as organizational attitudes, ethical beliefs, forms of governmental assistance, and cultural, geographical, and social-economic contexts will vary. This study is cross-sectional in nature; all measurements have been initiated at a single point due to practical constraints. Nevertheless, this research has tested a model that is based 
on theories and literature supported by empirical research. The approach undertaken in this research is a logical extension of previous studies, and that the variables and relationships tested are appropriate.

The study utilizes a set of three independent variables, two mediating variables and one dependent variable, not all of which would be equally important in a specific organizational setting. Moreover, some mediating effects that are related to the considered variables may have been ignored. Future research might incorporate more of these elements, for example, organizational structure, staff ranking systems and culture; these can also influence the adoption of sustainable technology.

Further research studies may also address the differences of sustainable technology between developed and developing countries. A cross-cultural study on its adoption might help us to understand attitudinal and perceptual differences between SMEs in several countries.

The sample has been chosen to represent the organizational perceptions of the role of government assistance regarding the adoption of sustainable technology. However, more research is needed to investigate other organizations that have actually implemented sustainability as a part of their organizational and business processes. This research has primarily focused on SMEs, so a wholly different outcome might be elicited by large organizations in developed and developing countries. Future research studies may aim to identify more antecedents in sustainable technology adoption, such as psychological conditions, religious belief, race, and ethnicity.

Finally, the model employed in this research study can be potentially applied to a large number of sustainable technology adoption issues and organizational problems. Future studies may seek to identify specific research topics in the area of sustainability management, so that they might benefit from the advanced theoretical research model developed here.

Author Contributions: M.F.A.B. and M.T. devised the study and the main conceptual ideas. A.Q. and I.K. were also involved during the development of conceptual model. All authors worked together to define the methodology of the study. M.F.A.B. and M.T. performed data analysis. A.Q. and I.K. aided in interpreting the results and worked on the manuscript. All authors have read and agreed to the published version of the manuscript.

Funding: This research received no external funding.

Conflicts of Interest: The authors declare no conflict of interest.

\section{Appendix A : Survey Questionnaire}

Section A-Organizational Characteristics

-How long has your organization been in operation?

More than 20 years, 16 to 20 years, 11 to 15 years, 6 to 10 years, Less than 5 years

-Please select the sector that best describes your organization.

Services Oriented, Product Oriented

-How many personnel are employed in your organization?

75-200 employees, 5-75 employees, Less than 5 employees

Please indicate or estimate your annual sales turnover for the last financial year.

MYR 15 million to MYR 50 million, MYR 300, 000 to MYR 15 million, Less than MYR 300, 000

\section{Section B-Determinants}

\section{Government Policies ( $1=$ Strongly Disagree, $7=$ Strongly Agree $)$}

- Government policy can attract more foreign investors to invest in sustainable businesses

- Government policy can encourage sustainable technology usage

- Government policy can improve sustainable technology efficiency

- Government policy can educate SMEs on the benefits of sustainable technology

- $\quad$ Overall, government policy helps SMEs to adopt sustainable technology 


\section{Government Support ( $1=$ Strongly Disagree, $7=$ Strongly Agree $)$}

- Government support can equip managers with skills to achieve sustainability

- Government support can educate employees to practice sustainability

- Government support can encourage conservation and pollution prevention efforts

- Government support can provide information on sustainable technology

- $\quad$ Overall, government support can help SMEs understand sustainability

\section{Government Subsidies (1 = Strongly Disagree, $7=$ Strongly Agree)}

- Government subsidies will decrease SMEs' investment costs

- $\quad$ Government subsidies will influence more SMEs to adopt sustainability

- Government subsidies can fund the development of sustainable innovation

- Government subsidies can reduce the risks in adopting sustainable technology

- Overall, government subsidies increase SMEs' interest in adopting sustainability

Organizational Attitudes (1 = Strongly Disagree, 7 = Strongly Agree)

- I feel proud to support sustainable technology implementation

- I feel positive towards sustainable technology adoption

- I believe sustainable technology can help improve the environment

- I believe sustainable technology can contribute to the country's development

- $\quad$ I agree with the idea of sustainable technology

- I will attend courses about sustainable technology

\section{Organizational Ethics (1 = Strongly Disagree, $7=$ Strongly Agree $)$}

- The state of the environment will affect the quality of SMEs

- $\quad$ SMEs need to respect the environment to survive in the current market

- I I am willing to adopt sustainable technology in order to protect the environment

- $\quad$ I am responsible for ensuring the environment is protected and sustained

- I feel obligated to save the environment for everyone's safety

- I I am ready to adopt sustainable technology for a better future for everyone

\section{Section C-Usage Level (Adoption)}

1. Frequency of usage: How frequently would your organization use sustainable technology for any related job?

Several times a day, Once a day, Once a week, Once a month, Less than once a month

2. Actual amount of time spent: How much time does your organization spend in one day on sustainable technology for any related job?

All the time, 6 to 8 hours, 4 to 6 hours, 2 to 4 hours, Less than 2 hours

3. Usage level: Please indicate your organization's level of usage when applying sustainable technology in any related job.

Used extensively, Used frequently, Used quite often, Used rarely, Not used at all

4. Amount of technology used: How many types of sustainable technology does your organization use? 
5. Sophistication level of technology used: How would you use a sophisticated sustainable technology in your organization?

Used extensively, Used frequently, Used quite often, Used rarely, Not used at all

\section{References}

1. Klewitz, J.; Hansen, E. Sustainability-oriented innovation of SMEs: A systematic review. J. Clean. Prod. 2014, 65, 57-75. [CrossRef]

2. Heiskanen, E.; Kasanen, P.; Timonen, P. Consumer participation in sustainable technology development. Int. J. Consum. Stud. 2005, 29, 98-107. [CrossRef]

3. Noppers, E.; Keizer, K.; Bolderdijk, J.; Steg, L. The adoption of sustainable innovations: Driven by symbolic and environmental motives. Glob. Environ. Chang. 2014, 25, 52-62. [CrossRef]

4. Koltun, P. Materials and sustainable development. Prog. Nat. Sci. Mater. Int. 2010, 20, 16-29. [CrossRef]

5. McMurray, A.; Islam, M.; Siwar, C.; Fien, J. Sustainable procurement in Malaysian organization: Practice, barriers and opportunities. J. Purch. Supply Manag. 2014, 20, 195-207. [CrossRef]

6. Forsman, H.; Temel, S. Innovation and business performance in small enterprises: An enterprises-level analysis. Int. J. Innov. Manag. 2011, 15, 641-665. [CrossRef]

7. Henriques, J.; Catarino, J. Sustainable value and cleaner production: Research and application in 19 Portuguese SME. J. Clean. Prod. 2014, 96, 379-386. [CrossRef]

8. Fargnoli, M.; Minicis, M.; Tronci, M. Design management for sustainability: An integrated approach for the development of sustainable products. J. Eng. Technol. Manag. 2014, 34, 29-45. [CrossRef]

9. Achabou, M.; Dekhili, S. Luxury and sustainable development: Is there a match? J. Bus. Res. 2013, 66, 1896-1903. [CrossRef]

10. Bocken, N.; Farracho, M.; Bosworth, R.; Kemp, R. The front-end of eco-innovation for eco-innovative small and medium sized companies. J. Eng. Technol. Manag. 2014, 31, 43-57. [CrossRef]

11. Papargyropoulou, E.; Padfield, R.; Harrison, O.; Preece, C. The rise of sustainability services for the built environment in Malaysia. Sustain. Cities Soc. 2012, 5, 44-51. [CrossRef]

12. Agamuthu, P.; Victor, D. Policy trends of extended producer responsibility in Malaysia. Waste Manag. Res. 2011, 29, 945-953. [CrossRef] [PubMed]

13. Oh, T.; Pang, S.; Chua, S. Energy policy and alternative energy in Malaysia: Issues and challenges for sustainable growth. Renew. Sustain. Energy Rev. 2010, 14, 1241-1252. [CrossRef]

14. Hashim, H.; Ho, W.S. Renewable energy policies and initiatives for a sustainable energy future in Malaysia. Renew. Sustain. Energy Rev. 2011, 15, 4780-4787. [CrossRef]

15. Cecere, G.; Corrocher, N.; Gossart, C.; Ozman, M. Technological pervasiveness and variety of innovators in Green ICT: A patent-based analysis. J. Res. Policy 2014, 43, 1827-1839. [CrossRef]

16. Muazu, A.; Yahya, A.; Ishak, W.; Khairunniza-Bejo, S. Energy audit for sustainable wetland paddy cultivation in Malaysia. J. Energy 2015, 87, 182-191. [CrossRef]

17. Abu Bakar, K.; Mohd Sam, M.F.; Tahir, N.H.; Rajiani, I.; Muslan, N. Green technology readiness in Malaysia: Sustainability for business development. J. Glob. Manag. 2011, 2, 1-11.

18. Zailani, S.; Jeyaraman, K.; Vengadasan, G.; Premkumar, R. Sustainable supply chain management (SSCM) in Malaysia: A survey. Int. J. Prod. Econ. 2012, 140, 330-340. [CrossRef]

19. ZainulAbidin, N. Investigating the awareness and application of sustainable construction concept by Malaysian Developers. J. Habitat Int. 2010, 34, 421-426. [CrossRef]

20. Cary, J.; Roberts, A. The limitations of environmental management systems in Australian agriculture. J. Environ. Manag. 2011, 92, 878-885. [CrossRef]

21. Fazeli, A.; Bakhtvar, F.; Jahanshaloo, L.; Sidik, N.; Bayat, A. Malaysia's stand on municipal solid waste conversion to energy: A review. Renew. Sustain. Energy Rev. 2016, 58, 1007-1016. [CrossRef]

22. Yazid, M.; Ismail, R.; Atiq, R. The use of non-motorized for sustainable transportation in Malaysia. Procedia Eng. 2011, 20, 125-134. [CrossRef]

23. Mohamed, A.; Lee, K. Energy for sustainable development in Malaysia: Energy policy and alternative energy. Energy Policy 2006, 34, 2388-2397. [CrossRef] 
24. Department of Statistics Current Population Estimates, Malaysia, 2018-2019. Available online: https: //www.dosm.gov.my (accessed on 28 January 2020).

25. Ong, J.; Ismail, H. Sustainable advantage through information technology competence: Resource-based view on small and medium enterprise. Commun. Ibima 2008, 1, 62-70.

26. Prediscan, M.; Roiban, R. The main forces driving change in the Romanian SME's. Procedia Soc. Behav. Sci. 2014, 124, 236-245. [CrossRef]

27. Ajzen, I.; Fishbein, M. The influence of attitudes on behavior. In The Handbook of Attitudes; Lawrence Erlbaum Associates: Mahwah, NJ, USA, 2005; pp. 173-221.

28. Sheppard, B.; Hartwick, J.; Warshaw, P. The theory of reasoned action: A meta analysis of past research with recommendations for modifications and future research. J. Consum. Res. 1988, 15, 325-343. [CrossRef]

29. Huijts, N.; Molin, E.; Steg, L. Psychological factors influencing sustainable energy technology acceptance: A review-based comprehensive framework. Renew. Sustain. Energy Rev. 2012, 16, 525-531. [CrossRef]

30. Doswell, W.M.; Braxter, B.J.; Cha, E.; Kim, K.H. Testing the theory of reasoned action in explaining sexual behavior among African American young teen girls. J. Pediatr. Nurs. 2011, 26, 45-54. [CrossRef]

31. Abdul-Manan, A.; Baharuddin, A.; Chang, L. Application of theory-based evaluation for the critical analysis of national biofuel policy: A case study in Malaysia. Eval. Program Plan. 2015, 52, 39-49. [CrossRef]

32. Sanchez, I.; Ruiz, J.; Lopez, J.; Perez, J. Effect of environmental regulation on the profitability of sustainable water use in the agro-food industry. Desalination 2011, 279, 252-257. [CrossRef]

33. Hansen, U.; Nygaard, I. Sustainable energy transitions in emerging economies: The formation of a palm oil biomass waste-to-energy niche in Malaysia 1990-2011. Energy Policy 2014, 66, 666-676. [CrossRef]

34. Victor, D.; Agamuthu, P. Strategic environmental assessment policy integration model for solid waste management in Malaysia. Environ. Sci. Policy 2013, 33, 233-245. [CrossRef]

35. Teixeira, A.; Jabbour, C.; Jabbour, A. Relationship between green management and environmental training in companies located in Brazil: A theoretical framework and case studies. Int. J. Prod. Econ. 2012, 140, 318-329. [CrossRef]

36. Igbaria, M.; Zinatelli, N.; Cragg, P.; Cavaye, A.L.M. Personal computing acceptance factors in small firms: A structural equation model. MIS Q. 1997, 21, 279-305. [CrossRef]

37. Mani, S. Government, innovation and technology policy: An international comparative analysis. Int. J. Technol. Globalisation 2004, 1, 29-44. [CrossRef]

38. Lin, H. Understanding the determinants of electronic supply chain management system adoption: Using the technology-organization-environment framework. J. Technol. Forecast. Soc. Chang. 2014, 86, 80-92. [CrossRef]

39. Guerrero, E.; Kim, A. Organizational structure, leadership and readiness for change and the implementation of organizational cultural competence in addiction health services. J. Eval. Program Plan. 2013, 40, 74-81. [CrossRef]

40. Nilakant, V.; Rao, H. Agency theory and uncertainty in organizations: An evaluation. Organ. Stud. 1994, 15, 649-672. [CrossRef]

41. Dasgupta, S.; Agarwal, D.; Ioannidis, A.; Gopalakrishnan, S. Determinants of information technology adoption: An extension of existing models to firms in a developing country. J. Glob. Inf. Manag. JGIM 1999, 7, 30-40. [CrossRef]

42. Sumaila, U.; Khan, A.; Teh, L.; Watson, R.; Tyedmers, P.; Pauly, D. Subsidies to high seas bottom trawl fleets and the sustainability of deep-sea demersal fish stocks. Mar. Policy 2010, 34, 495-497. [CrossRef]

43. Pavlou, P.A.; Fygenson, M. Understanding and predicting electronic commerce adoption: An extension of the theory of planned behavior. MIS Q. 2006, 30, 115-143. [CrossRef]

44. Gefen, D.; Benbasat, I.; Pavlou, P. A research agenda for trust in online environments. J. Manag. Inf. Syst. 2008, 24, 275-286. [CrossRef]

45. Zulfiqar, S.; Sarwar, B.; Aziz, S.; Chandia, K.E.; Khan, M.K. An analysis of influence of business simulation games on business school students' attitude and intention toward entrepreneurial activities. J. Educ. Comput. Res. 2019, 57, 106-130. [CrossRef]

46. Buijs, A.; Lawrence, A. Emotional conflicts in rational forestry: Towards a research agenda for understanding emotions in environmental conflicts. J. For. Policy Econ. 2013, 33, 104-111. [CrossRef]

47. Bhanthumnavin, D.; Bhanthumnavin, V. The empirical development of cognitive, affective, and behavioral tendency measures of attitudes towards nuclear power plants in Thai university students. Prog. Nucl. Energy. 2014, 73, 86-95. [CrossRef] 
48. Kortenkamp, K.; Moore, C. Ecocentrism and anthropocentrism: Moral reasoning about ecological commons dilemmas. J. Environ. Psychol. 2001, 21, 261-272. [CrossRef]

49. Klimova, A.; Rondeau, E.; Andersson, K.; Porras, J.; Rybin, A.; Zaslavsky, A. An international Master's program in green ICT as a contribution to sustainable development. J. Clean. Prod. 2016, 135, 223-239. [CrossRef]

50. Thompson, S.C.G.; Barton, M.A. Ecocentric and anthropocentric attitudes toward the environment. J. Environ. Psychol. 1994, 14, 149-157. [CrossRef]

51. Morgan, M.; Hine, D.; Bhullar, N.; Loi, N. Landholder adoption of low emission agriculture practice: A profiling approach. J. Environ. Psychol. 2015, 41, 35-44. [CrossRef]

52. Corral-Verdugo, V.; Bonnes, M.; Tapia-Fonllem, C.; Frajio-Sing, B.; Frias-Armenta, M.; Carrus, G. Correlates of pro-sustainability orientation: The affinity towards diversity. J. Environ. Psychol. 2009, 29, 34-43. [CrossRef]

53. Hirsh, J. Environmental sustainability and national personality. J. Environ. Psychol. 2014, 38, $233-240$. [CrossRef]

54. Moraes, T.; Millani, F. Altruism an evolutionary pathway: A review on the evolution of altruistic behavior. Rev. Fac. Cienc. Jurídicas Elche. 2014, 1, 65-82.

55. Legris, P.; Ingham, J.; Collerette, P. Why do people use information technology? A critical review of the technology acceptance model. Inf. Manag. 2003, 40, 191-204. [CrossRef]

56. Becker, J.-M.; Klein, K.; Wetzels, M. Hierarchical latent variable models in PLS-SEM: Guidelines for using reflective-formative type models. Long Range Plan. 2012, 45, 359-394. [CrossRef]

57. Fornell, C.; Larcker, D.F. Evaluating structural equation models with unobservable variables and measurement error. J. Mark. Res. 1981, 18, 39-50. [CrossRef]

58. Hair, J.; Sarstedt, M.; Pieper, T.; Ringle, C. The use of partial least squares structural equation modeling in strategic management research: A review of past practices and recommendations for future applications. Long Range Plan. 2012, 45, 320-340. [CrossRef]

59. Nunally, J.; Bernstein, I. Psychometric Theory; McGraw-Hill: New York, NY, USA, 1994.

60. Jaruwachirathanakul, B.; Fink, D. Internet banking adoption strategies for development country: The case of Thailand. Internet Res. 2005, 15, 295-311. [CrossRef]

61. Starik, M.; Rands, G.M. Weaving an Integrated Web: Multilevel and Multisystem Perspectives of Ecologically Sustainable Organizations. Acad. Manag. Rev. 1995, 20, 908-993. [CrossRef]

62. Yacob, P.; Wong, L.S.; Khor, S.C. An empirical investigation of green initiatives and environmental sustainability for manufacturing SMEs. J. Manuf. Technol. Manag. 2019, 30, 2-25. [CrossRef]

63. Bakar, F.A.; Talukder, M.; Khan, I.; Haque, E. Government role and sustainable technology adoption behaviours. In Proceedings of the ANZMAC 2019-Winds of Change: Australia and New Zealand Marketing Academy, Wellington, New Zealand, 2-4 December 2019; pp. 1360-1363.

64. Garcia-Johnson, R. Exporting Environmentalism: US Multinational Chemical Corporations in Brazil and Mexico; MIT Press: Cambridge, MA, USA, 2000.

65. Ratten, V. Entrepreneurial and ethical adoption behaviour of cloud computing. J. High Technol. Manag. Res. 2012, 23, 155-164. [CrossRef]

66. Kamble, S.; Gunasekaran, A.; Arha, H. Understanding the Blockchain technology adoption in supply chains-Indian context. Int. J. Prod. Res. 2019, 57, 2009-2033. [CrossRef]

67. Kaler, J.; Ruston, A. Technology adoption on farms: Using Normalisation Process Theory to understand sheep farmers' attitudes and behaviours in relation to using precision technology in flock management. Prev. Vet. Med. 2019, 170, 104715. [CrossRef] [PubMed]

(C) 2020 by the authors. Licensee MDPI, Basel, Switzerland. This article is an open access article distributed under the terms and conditions of the Creative Commons Attribution (CC BY) license (http://creativecommons.org/licenses/by/4.0/). 